\title{
TREATMENT OF CHRONIC PAIN IN CHILDREN WITH ONCOLOGICAL DISEASES (CASE REPORT)
}

\author{
Ischenko T. ${ }^{1}$, OmelchenkoO. ${ }^{1}$, Marinich L. ${ }^{2}$, Orlova ${ }^{1}{ }^{1}$ \\ Department of Pediatrics No. 1 and Neonatology ${ }^{1}$ \\ Kharkiv National Medical University, Ukraine \\ Kharkov City Children's Clinical Hospital No. 16 \\ Kharkov, Ukraine
}

\begin{abstract}
Acute myeloid leukemia accounts for about $4.2 \%$ of all forms of cancer in children and adolescents. Significant progress has been made in the treatment of oncohematological pathology in recent years, especially in the treatment of lymphoblastic leukemia (survival rate is up to $80 \%$ ). However, unsolved problems remain in many diseases, in particular in myeloid leukemia, in which the survival rate is $38-41 \%$. In this regard, the most critical issue is the provision of care for children with an unfavorable prognosis with malignant neoplasms. The death of a child is always incredibly difficult to accept, but understanding the feelings that causes death can help find the right approach to proper organization and provision of care for critically ill patients at the end of life.
\end{abstract}

Key words: chronic pain, children, palliative care, oncological blood diseases.

"Heal sometimes, heal often, comfort always"

Ambroise Paré 1510-1590

Relevance. Acute myeloid leukemia accounts for about $4.2 \%$ of all forms of cancer in children and adolescents. Significant progress has been made in the treatment of oncohematological pathology in recent years, especially in the treatment of lymphoblastic leukemia (survival rate is up to $80 \%$ ). However, unsolved problems remain in many diseases, in particular in myeloid leukemia, in which the survival rate is $38-41 \%$. In this regard, the most critical issue is the provision of care for children with an unfavorable prognosis with malignant neoplasms. The death of a child is always incredibly difficult to accept, but understanding the feelings that causes death can help find the right approach to proper organization and provision of care for critically ill patients at the end of life.

Corresponding Author:

Tatiana Isñhenko, MD, PhD, Associate Professor, Department of Pediatrics 1 and Neonatology, Kharkiv National Medical University, Ukraine. E-mail: 7tanyatb7@gmail.com

\section{Clinical case}

A 12-year-old child M. was brought to the hematological department with diagnosis: acute leukemia, myeloid variant M0, undifferentiated, second bone marrow relapse.

According to his medical history the child received polychemotherapy for acute myeloid leukemia for 6 months as part of the OML-95 program (chemotherapy protocol for the treatment of myeloid leukemia). After the main therapy, the child's condition improved, clinicohematologic remission was achieved and the child was discharged home.

After 3 months the child's condition deteriorated sharply: he developed intoxication and hemorrhagic syndrome, in connection with which the child re-entered the hospital and was diagnosed with bone marrow relapse. As a result, palliative chemotherapy was started, in view of the non-curability of this case. I chemotherapy block was effective and the child was diagnosed with II clinical-hematologic remission (absence of blast cells in the periphery and less than $5 \%$ in the bone marrow). After 28 days, the condition deteriorated sharply (due to toxic-septic state, DIC syndrome) secondary to the second bone 
marrow relapse in connection with which palliative chemotherapy was continued.

Psychological aspects of the clinical case: the child was with the parents when the child was admitted and diagnosed, the diagnosis was made on the third day of the patient's stay in the hospital, which was communicated to the parents and the patient in the presence of the attending physician and the head of the department. It was also reported that the child entered a high risk group with a 38-41\% survival rate. Parents of the patient took this information negatively, because they had an opportunity to observe patients in the department who received chemotherapy, and the results of the therapy were evident in these patients in the form of "Cushing's", alopecia and more serious complications. However, through a deep conversation with the mother of the child, the medical staff of the department managed to convince the expediency of protocol therapy. On the 15th day of chemotherapy, bone marrow remission was obtained, and the parents reacted positively to the continuation of therapy.

At the same time, parents had confidence in the medical staff. While the child was undergoing chemotherapy, the department was visited as part of the delegation of the "GLOBAL 2000" sponsorship fund, specialists in oncohematology from GermanyHe said: "Your child has no chances. Keep up your spirit!" After that the mother of the child refused to care for him and the child was transferred to the intensive care unit, where he spent the last days of his life, without relatives.

In recent decades, great advances have been made in the treatment of children with oncohematological diseases [4, 5]. Despite the use of intensive modern chemotherapy programs, complex treatment, a certain part of children with oncology is recognized as incurable at a certain stage, and therapeutic measures are directed not at attempts to completely cure the patient, but to alleviate his condition. It is extremely important to develop a strategy for care at the end of a child's life that will help provide effective palliative care, as well as support for all people involved in caring for it [6].

The problem of providing palliative care to children is extremely relevant and attracts the attention of many specialists in various countries of the world. There is lack of qualifies staff to care for children with potentially lethal diseases [7].

Psychological aspects (feelings of guilt, fear, personal suffering experienced by parents and health professionals) are a complex problem. Parents in some cases do not recognize the plight and incurability of the child and grieve, can lose vital signs and change their behavior $[8,9]$.

Understanding what is ahead, and the opportunity to alleviate suffering at the end of life, positively affects people who are suffering a loss. Pediatric palliative care is an active, comprehensive help to the body, mind and spirit of the child and family. It requires a broad interdisciplinary approach that mitigates the physical, psychological and social distress of the child, includes family members and uses available resources of society $[10,11]$.

The issue of training staff and specialists relevant to the provision of palliative care for children is extremely important. The wellcoordinated work of the team of qualified specialists of children's palliative care can help organize round-the-clock assistance with patient's family and friends, as well as professional medical, psychosocial and spiritual support. Controlling the symptoms of the disease and alleviating the patient's condition are of paramount importance at the end of patient's life [12-15].

Conclusions. Thus, palliative care is created to alleviate the state of health, as the child himself, who suffers and experiences pain from the progression of the incurable disease, and his parents and other relatives, including healthy brothers and sisters who experience not only stress, but also psychological trauma both during illness and after separation.

\section{References}

1. WHO guidelines on the pharmacological treatment of persisting pain in children with medical illnesses (2012). Publications of the World Health Î rganization, ð. 166. Àvailable at: http://apps.who.int/ iris/bitstream/10665/44540/1/9789241548120_Guidelines.pdf

2. Lulu Mathews (2011). Pain in Children: Neglected, Unaddressed and Mismanaged. Indian J Palliat Care, 17, ðð. 70-73.

a. doi: 10.4103/0973-1075.76247

3. Hofman, M. et al (2007). Posttraumatic stress disorder in children affected by sickle-cell disease and their parents. American Journal of Hematology, 82, ðð. 171-172. 
4. McGrath, P.A. (1996). Development of the World Health Organization Guidelines on Cancer Pain Relief and Palliative Care in Children. J Pain Symptom Manage, 12, ð. 87.

5. John Martin Goddard (2014). Chronic pain in Children and Young People. Pediatrics and Child Health, 24(2), ðð. 89-91.

doi: http://dx.doi.org/10.1016/j.paed.2013.08.005

6. Stefan J Friedrichsdorf and Andrea Postier (2014). Management of breakthrough pain in children with cancer. J Pain Res. ðð. 117-123.

doi: 10.2147/JPR.S58862

7. Theunissen, J.M., et al. (2007). Symptoms in the palliative phase of children with cancer. Pediatr Blood Cancer, 49(2), pð. 160-165.

8. Walsh, D., Donnelly, S. and Rybicki, L. (2000). The symptoms of advanced cancer: relationship to age, gender, and performance status in 1,000 patients. Support Care Cancer, 8(3), pð. 175-179.

9. Wolfe, J., et al. (2000). Symptoms and suffering at the end of life in children with cancer. N Engl J Med, 342(5), pð. 326-333.

10.Cartoni, C., et al. (2009). Hemorrhagic complications in patients with advanced hematological malignancies followed at home: an Italian experience. Leuk Lymphoma, 50(3), pð. 387-391.

11. Hongo, T., et al. (2003). Analysis of the circumstances at the end of life in children with cancer: symptoms, suffering andacceptance. Pediatr Int, 45(1), pð. 60-4.

12.Selwood, K. (2006). Constipation in paediatric oncology. Eur J Oncol Nurs, 10(1), pð. 68-70.

13.Weschules, D.J., et al. (2006). Toward evidence-based prescribing at end of life: a comparative analysis of sustainedrelease morphine, oxycodone, and transdermal fentanyl, with pain, constipation, and caregiver interaction outcomes in hospice patients. Pain Med, 7(4), pð. 320-329.

14. Woolery, M., et al. (2006). A constipation assessment scale for use in pediatric oncology. J Pediatr Oncol Nurs, 23(2), pð. 65-74.

15. Loeser, J.D., Treede, R.D. (2008). The Kyoto protocol of IASP Basic Pain Terminology. Pain, 137, рð.473-477. 